\title{
Site and Type Assessments of Sports Injuries in Archers
}

\section{Okçularda Spor Yaralanmaları Bölgelerinin ve Türlerinin Değerlendirilmesi}

\author{
Gizem Kocaman ${ }^{1}$, Emrah Atay², Mahmut Alp ${ }^{3}$, Gürhan Suna ${ }^{3}$ \\ ${ }^{1}$ Mehmet Akif Ersoy University, Institute of Social Sciences, Department of Management, Burdur, Turkey \\ ${ }^{2}$ Mehmet Akif Ersoy University, School of Physical Education and Sports, Department of Sports Administration, \\ Burdur, Turkey \\ ${ }^{3}$ Süleyman Demirel University, Faculty of Sports Sciences, Department of Sports Sciences, Isparta, Turkey
}

\section{G. Kocaman \\ 0000-0001-6008-7329 \\ E. Atay \\ 0000-0003-4404-6804 \\ M. Alp \\ 0000-0002-1263-2633 \\ G. Suna \\ 0000-0002-2125-9105}

Geliş Tarihi / Date Received: 28.09.2017

Kabul Tarihi / Date Accepted: 14.11.2017

Yayın Tarihi / Date Published: 02.03.2018

Yazışma Adresi /

Corresponding Author:

Mahmut Alp

Süleyman Demirel Üniversitesi

Spor Bilimleri Fakültesi,

Spor Bilimleri Anabilim Dalı,

Isparta, Turkey.

E-mail:

mahmut.alp@windowslive.com

(C)2018 Türkiye Spor Hekimleri Derneği. Tüm hakları saklıdır.

\section{ABSTRACT}

Objective: The purpose of this study is to assess the types of musculoskeletal injuries and injured areas of athletes participating in archery competitions.

Materials and Methods: Forty-seven females (31.1\%) and 104 males (68.9\%), totally 151 archers joined voluntarily the study. Their mean age was $20.4 \pm 3.4$ years, height was $173.5 \pm 7.7 \mathrm{~cm}$, and body weight was $69.0 \pm 11.2 \mathrm{~kg}$. About $58.9 \%(\mathrm{n}=89)$ of participants were using the classical bow, and $41.1 \%(n=62)$ the compound bow. The "Musculoskeletal System Questionnaire" was used to evaluate the archers' injuries. In the questionnaire, nine body sections were divided into neck, shoulder, elbow, wrist, back, waist, hip-thigh, knee, foot-foot wrist. The questionnaire questioned the athletes' injuries during the last 12 months. In the data evaluation, the statistical program developed for social sciences was utilized. The results were evaluated as frequency, percentage distribution, chi-square tests. The level of significance was accepted as $p<0.05$.

Results: The most injured areas of the athletes were the shoulders as $27.5 \%(n=60)$, the neck as $18.3 \%(n=40)$, and the back as $16.1 \%(n=35)$. When disability evaluation is performed according to categories (classical bow, spiral spring), the prevalent injured body regions did not change The incidence of injuries in the compound bow was lower, but the difference was not statistically significant $(p>0.05)$. The most common type of injury in all three regions was muscle pain. About $57.6 \%$ of these injuries occurred during training. About $35.0 \%$ of injuries were cured in a health facility.

Conclusion: Most archers are injured in the shoulder, neck and back areas. These injuries are mostly seen as muscle pain. The vast majority of injuries occur in training. In archers, shoulder, neck, and back areas should be more strengthened to reduce injuries. Extra warm-up programmes special to muscles in these sections should be especially applied in trainings and competitions. Shooting techniques are to be correctly applied.

Key Words: Sports injuries, back injuries, neck injuries, shoulder injuries, archery

\section{$\ddot{Z z}$}

Amaç: Bu çalışmanın amacı okçuluk müsabakalarına katılan sporcuların kas-iskelet sistemi yaralanma türlerini, yaralandıkları bölgelerin ve yaralanma zamanının belirlenmesidir.

Gereç ve Yöntemler: Çalışmaya ortalama yaşları $20.4 \pm 3.4$ yıl, boyları $173.5 \pm 7.7 \mathrm{~cm}$, vücut ağırlığı 69.0 \pm 11.2 kg olan 104'ü erkek (\%68.9), 47'si kadın (\%31.1) toplam 151 sporcu gönüllü olarak katıldı. Katılımcıların \%58.9'u ( $n=89)$ klasik yay, \%41.1'i ( $n=62)$ makaralı yay kullanmaktaydılar. Yaralanmaları değerlendirmede "Kas-İskelet Sistemi Anketi" kullanıldı. Ankette vücut dokuz bölüme ayrılmıştır. Anket sporcunun son bir yıllık periyottaki yaralanmalarını sorgulamaktadır. Verilerin değerlendirilmesinde "Sosyal Bilimler için 
Geliştirilen İstatistik Programı”ndan yararlanıldı. Sonuçlar frekans, yüzde dağılımı ve ki-kare testleri ile değerlendirildi. Anlamlılık düzeyi $p<0.05$ olarak kabul edildi.

Bulgular: Sporcuların en fazla yaralandıkları bölgeler sırasıyla omuz \%27.5 $(n=60)$, boyun \%18.3 $(n=40)$, sırt \%16.1 $(n=35)$ bölgeleriydi. Kategorilere (klasik yay, makaralı yay) göre yaralanma değerlendirmesi yapıldığında en fazla yaralanmanın görüldüğü vücut bölgeleri değişmemektedir. Klasik yayda meydana gelen yaralanma görülme oranı makaralı yaya göre daha yüksek olmasına rağmen, aradaki fark istatistiksel olarak anlamlı düzeyde değildi ( $p>0.05$ ). Her üç bölgede de en çok görülen yaralanma türü kas ağrısı ve zorlanma idi. Bu yaralanmaların \%57.6'sı antrenmanda meydana gelmişti. Yaralanmaların \%35.0’i bir sağlık kuruluşunda tedavi edilmişti.

Sonuç: Okçular en çok omuz, boyun ve sırt bölgesinden yaralanmaktadır. Bu yaralanmalar en çok kas ağrısı ve zorlanma şeklindedir. Yaralanmaların büyük çoğunluğu antrenmanda meydana gelmektedir. Okçularda yaralanmaların azaltılması için omuz, boyun ve sırt bölgeleri daha çok kuvvetlendirilmelidir. Özellikle antrenman ve müsabakalarda bu bölge kaslarına özgü ekstra ısınma programı uygulanmalıdır. Atış tekniklerinin doğru uygulandığından emin olunmalıdır.

Anahtar Sözcükler: Spor yaralanmaları, sırt yaralanmaları, boyun yaralanmaları, omuz yaralanmaları, okçuluk

Not: Bu çalışma 4. Spor Bilimleri, Turizm ve Rekreasyon Öğrenci Kongresi'nde (21-23 Nisan, 2017) poster bildiri olarak kabul edilmiştir.

Available at: http://journalofsportsmedicine.org and http://dx.doi.org/10.5152/tjsm.2018.084

Cite this article as: Kocaman G, Atay E, Alp M, et al. Site and type assessments of sports injuries in archers. Turk $J$ Sports Med. 2018;53:1-8.

\section{GİRIŞ}

Günümüzde spor çok sayıda uygulama dalı bulunan; hem profesyonel, hem de amatör olarak yaygın bir şekilde yapılan uğraş haline dönmüştür. Sporun sağlıklı yaşamın ön koşulu olarak kabul edildiği günümüzde, kabul edilen başka bir gerçek de spor sırasında oluşan yaralanmalardır (1).

Spor yaralanmaları genel olarak sportif aktiviteler sırasında meydana gelen her türlü hasara verilen bir isimdir. Vücudumuzda fiziksel aktiviteler sonucu meydana gelen bu hasarlar birçok nedenle ortaya çıkabilmektedir (2). Dünya Sağlık Örgütü (WHO)'nün özürlü sinıflandırmada kullanılan bozulma kavramına dayanan, spor katılımıyla ilişkili sağlık sorunları spor yaralanmaları olarak tanımlanmaktadır (3). Başka bir deyişle, spor yaralanmaları etiyolojik olarak, vücut işlevlerinin kaybedilmesi veya spor katılımı sırasında enerji transferinden kaynaklanan yapının sapması olarak da tanımlanmaktadır (4).

Spor yaralanmaları 1-7 gün süren hafif yaralanmalar, 8-21 gün süren orta düzey yaralanmalar ve 21 günden fazla süren ciddi yaralanmalar olarak sinıflandırılır (5).

Spor yaralanmaları sporcunun performansını ve beceri düzeyini olumsuz etkileyen istenmedik bir olaydır (6). Eğer sporcunun başarılı olması isteniyorsa, yaralanmadan uzak kalması gerekir. Bunun için yaralanmanın oluşmasından ziyade, yaralanmanın önüne geçilmesi daha önemli duruma gelmektedir (7).

Sporda yaralanma tipi ve bölgesi sporcunun yaşına ve cinsiyetine göre değişkenlik gösterir. Bu nedenle sporcuların sportif yaralanmalarındaki farklılıkları bilmek ve tedavi planını bu doğrultuda yapmak önem teșkil eder (2).

Hekimlerin ve diğer sporcu sağlığı çalışanlarının doğru tanı ve tedavi yaklaşımları sergileyebilmek için yaş gruplarına özgü anatomik, fizyolojik farklılıkları ve yaralanmaları iyi tanımaları gerekir. Ayrıca yaralanmaların önlenmesine yönelik prensipler konusunda aile, sporcu ve antrenörlere gerekli destek sağlanmalıdır (8).

Sporcunun fiziksel uygunluğuna göre planlanan antrenman programları, spor yaralanmalarından korunma yöntemlerinin uygulanması, oluşan yaralanmanın tedavisi ve rehabilitasyonu gibi önemli faktörlere gösterilen özen, yaralanmalarda belirleyicidir $(9,10)$.

Tüm spor dallarında olduğu gibi, okçuluk sporunda da var olan yaralanma risklerinin önüne geçilmesi ve oluşan yaralanmaların uygun bir şekilde tedavi edilebilmesi sporcu başarısının 
devamında önemli bir yer tutar. Bu nedenle, okçuluk branşında oluşabilecek yaralanmaların neler olabileceğinin ve bunlara yol açan nedenlerin önceden bilinmesinin alınacak tedbirler açısından önemlidir (11). Literatürde okçuluğun statik niteliğiyle ilişkili çok az bilgi bulunmaktadır. Okçulukta omuz yaralanmalarının incelendiği bir çalışmada 21 elit okçuda omuz yaralanmalarının oranının yüksek olduğu ve bu yaralanmaların anatomik diseksiyonlarla gözlenene koşut olduğu vurgulanmıştır (12).

Başka bir çalışmada, çekiş kolundaki en yaygın yaralanma türü omuz yaralanmaları olarak saptanmiştır. Bunun nedeni olarak rotator cuff kaslarına uygulanan antrenmanların yetersizliği, aşırı antrenman ve yanlış teknik uygulamaları gösterilmiștir (13).

Literatürden elde edilen bilgiler doğrultusunda, bu çalışmanın amacı, Türkiye Şampiyonasına katılan okçuların kas-iskelet sistemi yaralanma türlerinin, yaralandıkları bölgelerin ve yaralanma zamanının değerlendirilmesidir.

\section{GEREÇ ve YÖNTEMLER}

Çalışmaya ortalama yaşları $20.4 \pm 3.4$ yıl, boyları $173.5 \pm 7.7 \mathrm{~cm}$, vücut ağırlıkları $69.0 \pm 11.2 \mathrm{~kg}$ olan 104'ü erkek (\%68.9), 47'si kadın (\%31.1) toplam 151 okçuluk sporcusu gönüllü olarak katıldı. Katılımcıların \%58.9'u (n=89) klasik yay, \%41.1'i $(\mathrm{n}=62)$ makaralı yay kullanmaktaydılar. Okçuların yaralanmalarını değerlendirmede daha önce güvenilirliği ve geçerliliği kanıtlanmış olan "Kas-İskelet Sistemi Anketi" kullanıldı (14). Ankette boyun, omuz, dirsek, el bileği, sirt, bel, kalça-uyluk, diz, ayak-ayak bileği olmak üzere dokuz vücut bölümü ayrılmıştır. Anket formu kişisel görüşme tekniği ile dolduruldu. Anket sporcunun son bir yll içerisinde geçirdiği yaralanmalarını sorgulamaktadır.

\section{İstatistiksel Analiz:}

Verilerin değerlendirilmesinde sosyal bilimler için geliştirilen istatistik programından yararlanıldı. Sonuçlar frekans, yüzde dağılımı ve ki-kare testleri ile değerlendirildi. Anlamlılık düzeyi " $\mathrm{p}<0.05$ " olarak kabul edildi.

\section{BULGULAR}

Tablo 1 incelendiğinde, toplam 218 yaralanmanın meydana geldiği görülmektedir. Yaralanmaların 141'i (\%64.5) klasik yay kullanan sporcularda, 77'si ise (\%35.5) makaralı yay kullananlarda olmuştur. En fazla yaralanmanın meydana geldiği vücut bölgeleri omuz (\%27.5), boyun (\%18.3), ve sirt (\%16.1) bölgeleridir. Kategorilere göre tüm vücut bölgelerinde klasik yay kullananların yaralanma sıklıkları daha yüksek olmasına karşın, aradaki fark istatistiksel olarak anlamlı düzeyde değildi ( $p>0.05)$. Yaralanmaların içerisinde en fazla meydana gelen yaralanma türü zorlanma ve kas ağrısı idi (Tablo 2).

Tablo 3'de de görüldügü üzere, yaralanmalar büyük oranda antrenmanlarda meydana gelmiștir. Antrenmanlarda yaralanmalar en fazla omuz, sirt ve boyun bölgelerinde söz konusu olmuştur.

Sporcuların maruz kaldıkları 218 yaralanmanın \%34.9'u (n=76) sağlık kuruluşlarında tedavi edilmiştir. Sağlık kuruluşlarına başvurular en sık omuz ve boyun bölgelerinde meydana gelen yaralanmalar ile ilişkiliydi (Tablo 4). 
Tablo 1. Kategorilere göre vücut bölgelerinde yaralanma sıklıklarının değerlendirilmesi

\begin{tabular}{|c|c|c|c|c|c|c|c|}
\hline \multirow[t]{2}{*}{$\begin{array}{l}\text { Yaralanan } \\
\text { vücut bölgesi }\end{array}$} & \multirow[t]{2}{*}{ Kategori } & \multicolumn{2}{|c|}{$\begin{array}{l}\text { Yaralanma } \\
\text { sayı / oranı }\end{array}$} & \multicolumn{2}{|c|}{$\begin{array}{c}\text { Toplam } \\
\text { sayı / oranı }\end{array}$} & \multirow[t]{2}{*}{ df } & \multirow[t]{2}{*}{$\mathbf{p}$} \\
\hline & & $(n)$ & $(\%)$ & (n) & $(\%)$ & & \\
\hline \multirow{2}{*}{ Boyun } & Klasik yay & 24 & 60.0 & \multirow{2}{*}{40} & \multirow{2}{*}{18.3} & \multirow{2}{*}{1} & \multirow{2}{*}{.874} \\
\hline & Makaralı yay & 16 & 40.0 & & & & \\
\hline \multirow{2}{*}{ Omuz } & Klasik yay & 41 & 68.3 & \multirow{2}{*}{60} & \multirow{2}{*}{27.5} & \multirow{2}{*}{3} & \multirow{2}{*}{.115} \\
\hline & Makaralı yay & 19 & 31.7 & & & & \\
\hline \multirow[t]{2}{*}{ Dirsek } & Klasik yay & 11 & 61.1 & \multirow{2}{*}{18} & \multirow{2}{*}{8.3} & \multirow{2}{*}{3} & \multirow{2}{*}{.955} \\
\hline & Makaralı yay & 7 & 31.7 & & & & \\
\hline \multirow{2}{*}{ El-el bileği } & Klasik yay & 14 & 61.1 & \multirow{2}{*}{23} & \multirow{2}{*}{10.1} & \multirow{2}{*}{3} & \multirow{2}{*}{.313} \\
\hline & Makaralı yay & 9 & 38.9 & & & & \\
\hline \multirow{2}{*}{ Sirt } & Klasik yay & 23 & 65.7 & \multirow{2}{*}{35} & \multirow{2}{*}{16.1} & \multirow{2}{*}{1} & \multirow{2}{*}{.434} \\
\hline & Makaralı yay & 12 & 34.3 & & & & \\
\hline \multirow{2}{*}{ Bel } & Klasik yay & 10 & 52.6 & \multirow{2}{*}{19} & \multirow{2}{*}{8.7} & \multirow{2}{*}{1} & \\
\hline & Makaralı yay & 9 & 47.4 & & & & \\
\hline & Klasik yay & 5 & 100 & & & & \\
\hline & Makaralı yay & - & - & & & & \\
\hline & Klasik yay & 11 & 68.8 & & & & \\
\hline Diz & Makaralı yay & 5 & 31.3 & 16 & 7.3 & 1 & .436 \\
\hline Ayak-ayak & Klasik yay & 2 & 100 & & & & \\
\hline Dife & Makaralı yay & - & - & & & & \\
\hline
\end{tabular}


Tablo 2. Kategorilere göre en fazla görülen yaralanma türlerinin (zorlanma-kas ağrısı) bölgelere göre sıklıkları ve toplam yaralanma sıklığına $(n=217)$ göre oranları

\begin{tabular}{|c|c|c|c|c|c|c|c|c|}
\hline \multirow[t]{3}{*}{ Vücut bölgesi } & \multicolumn{4}{|c|}{ Klasik yay } & \multicolumn{4}{|c|}{ Makaralı yay } \\
\hline & \multicolumn{2}{|c|}{ Zorlanma } & \multicolumn{2}{|c|}{ Kas ağrısı } & \multicolumn{2}{|c|}{ Zorlanma } & \multicolumn{2}{|c|}{ Kas ağrısı } \\
\hline & $\mathrm{n}$ & $\%$ & $\mathrm{n}$ & $\%$ & $\mathrm{n}$ & $\%$ & $\mathrm{n}$ & $\%$ \\
\hline Boyun & 8 & 3.68 & 13 & 5.99 & 5 & 2.30 & 9 & 4.14 \\
\hline Omuz & 12 & 5.53 & 19 & 8.75 & 5 & 2.30 & 9 & 4.14 \\
\hline Dirsek & 5 & 2.30 & 3 & 1.38 & 3 & 1.38 & 2 & 0.92 \\
\hline El-el bileği & 6 & 2.76 & 5 & 2.30 & 2 & 0.92 & - & - \\
\hline Sirt & 7 & 3.22 & 13 & 5.99 & 3 & 1.38 & 7 & 3.22 \\
\hline Bel & 3 & 1.38 & 6 & 2.76 & 3 & 1.38 & 5 & 2.30 \\
\hline Kalça & 2 & 0.92 & - & - & - & & - & \\
\hline Diz & 5 & 2.30 & - & - & 1 & 0.46 & 2 & 0.92 \\
\hline Ayak-ayak bileği & - & - & - & & - & & - & \\
\hline Toplam & 48 & 22.1 & 59 & 27.1 & 22 & 10.1 & 34 & 15.7 \\
\hline
\end{tabular}

Tablo 3. Yaralanma nedeni ile sağlık kuruluşlarına başvurma sıklıkları ve oranları

\begin{tabular}{lcc}
\hline Vücut bölgesi & $\mathbf{n}$ & $\%$ \\
\hline Boyun & 13 & 6.0 \\
\hline Omuz & 25 & 11.5 \\
\hline Dirsek & 9 & 4.1 \\
\hline El-el bileği & 10 & 4.6 \\
\hline Sırt & 3 & 1.4 \\
\hline Bel & 7 & 3.2 \\
\hline Kalça & 3 & 1.4 \\
\hline Diz & 4 & 1.8 \\
\hline Ayak-ayak bileği & 2 & 0.9 \\
\hline Toplam & 76 & 35.0 \\
\hline
\end{tabular}


Tablo 4. Yaralanmaların meydana gelme zamanı

\begin{tabular}{lcccccccc}
\hline Vücut bölgesi & \multicolumn{2}{c}{ Antrenman } & \multicolumn{2}{c}{ Müsabaka } & \multicolumn{2}{c}{ Diğer } & \multicolumn{2}{c}{ Toplam } \\
\cline { 2 - 9 } & $\mathrm{n}$ & $\%$ & $\mathrm{n}$ & $\%$ & $\mathrm{n}$ & $\%$ & $\mathrm{n}$ & $\%$ \\
\hline Boyun & 22 & 10.1 & 8 & 3.68 & 10 & 4.6 & 40 & 18.4 \\
\hline Omuz & 46 & 21.2 & 3 & 1.38 & 11 & 5.1 & 60 & 27.6 \\
\hline Dirsek & 12 & 5.5 & 3 & 1.38 & 3 & 1.4 & 18 & 8.3 \\
\hline El-el bileği & 11 & 5.1 & 1 & 0.46 & 11 & 5.1 & 23 & 10.6 \\
\hline Sirt & 24 & 11.1 & 3 & 1.38 & 8 & 3.7 & 35 & 16.1 \\
\hline Bel & 4 & 1.8 & 2 & 0.92 & 13 & 6.0 & 19 & 8.8 \\
\hline Kalça & 1 & 0.5 & 4 & 1.84 & - & & 5 & 2.3 \\
\hline Diz & 3 & 1.4 & - & & 13 & 6.0 & 16 & 6.4 \\
\hline Ayak-ayak bileği & 2 & 0.9 & - & & - & & 2 & 0.9 \\
\hline Toplam & 125 & 57.6 & 24 & 11.0 & 69 & 31.8 & 218 & 100 \\
\hline
\end{tabular}

\section{TARTIȘMA}

$\mathrm{Bu}$ çalışmada okçuların yaralanma bölgeleri değerlendirildiğinde en fazla yaralanmanın sirasiyla omuz \%27.5 (n=60), boyun \%18.3 $(n=40)$ ve sirt \%16.1 (n=35) bölgelerinde olduğu ortaya konmuştur. Kategorilere (klasik veya makaralı yay) göre yaralanma değerlendirmesi yapıldığında, en fazla yaralanmanın görüldügü vücut bölgeleri değişmemektedir. Makaralı yayda meydana gelen yaralanma görülme oranı daha düșük olmasına rağmen, aradaki fark istatistiksel olarak anlamlı düzeyde değildi ( $p>0.05)$. Okçular her üç bölgede de en çok görülen yaralanma türünün kas ağrısı ve zorlanma olduğunu belirtmişlerdir. Yaralanmaların büyük oranda antrenmanlarda meydana geldiği anlaşılmaktadır.

Okçuluk sporunda meydana gelen yaralanmaların yaklaşık üçte biri sağlık kuruluşlarında tedavi gerektirmiştir. Sporcuların ok atışına başlamadan önce gerekli ısınma egzersizlerini yapmaları önem taşır. Bunun yanı sıra, okçularda omuz yaralanmalarının sık görülme nedeni olarak yoğun antrenmanlar ve yanlış teknik ile birleșen rotator cuff kaslarında kuvvet eksikliği belirtilmektedir. Okçuluk, üst ekstremite gücü, omuz bölgesi kaslarının kuvveti gibi statik kasılmalara gereksinim duyan bir spor dalıdır. Çoğu yaralanmalar vücuda uygulanan asimetrik yük ve kuvvetten kaynaklanmaktadır (15). Uluslararası bir yarışmada erkek bir okçunun dört gün boyunca günde en az 75 yayın her birini $45 \mathrm{lbf}$ kuvvetle çektiği ifade edilmektedir (16).

Bu durum sporcunun kemik, kas ve bağ yapılarına günde 1546 kg ağırlığın binmesi gerektiğini ve ilgili spor yaralanmalarına neden olabileceği görüşüne kaynak olmuştur (17).

Okçuluk spor dalında; sporcuların antrenmanda yaralanma nedenlerinin incelenmiş olduğu bir araştırmada; çalışmaya katılan 389 sporcudan 370'inin bu soruya verdiği yanıtlara göre; sporcuların \%4.3'ünün bilinçsiz hareketten, \%5.9'unun koruyucu malzeme kullanmamaktan, \%0.5'inin yetersiz malzemeden, \%38.1'inin yetersiz ısınmış olmaktan, \%28.4'ünün aşırı yüklenmeden, \%11.9'unun düzensiz antrenman yapmaktan, \%1.6'sının alan yetersizliği nedenli, $\% 8.6$ 'sının farklı nedenlerden dolayı, \%0.5'inin ise birden fazla nedenden dolayı yaralanma geçirebilecekleri saptanmıştır. Okçular büyük bir oranda (\%67.5) antrenmanda geçirdikleri 
yaralanmanın nedeni olarak yetersiz isınmayı ve aşırı yüklenmeyi öne sürmüşlerdir (18).

Okçuların antrenman sırasında geçirdikleri spor yaralanmalarının etkilediği vücut bölgelerine göre dağılımlarına bakıldığında; \%7.7 ayak- ayak bileği bölgesi, \%7.7 baldır-uyluk bölgesi, \%30.8 el-el bileği bölgesi, \%6.4 diz bölgesi, \%37.2 omuz bölgesi, \%2.6 bel bölgesi, \%2.6 baș bölgesi, \%5.1 diğer bölgeler etkilediği gözlendi. Okçulukta yay çekme kolu, el bileği ve parmaklar antrenman ve müsabaka sırasında tekrarlayan kuvvetlerle karşı karşıya kalmaktadır. Yayın bırakılması sırasında yapılacak olan bir yanlış, serbest bırakma el bileğinde lateral sapmalara neden olabilmektedir. Bu nedenle de lateral sapmaların el bileği yaralanmalarına zemin hazırladığ bildirilmiştir (19).

Elit okçularda akut ve aşırı kullanıma bağlı yaralanmalar incelendiğinde; aşırı yaralanmalar çoğunlukla omuzda ( $\mathrm{n}=27, \% 52.9)$, daha doğrusu çekiş kolu omuzunda (\%64.7) bulundu. İkinci aşırı kullanıma bağlı yaralanmaların da kolda $(\mathrm{n}=12, \% 23.5)$, öncelikle de yay kolunda (\%66.7) olduğu saptandı. Okçulardaki aşırı kullanım yaralanmalarının oluşum ve lokalizasyonunun, yük altındaki spesifik tekrarlanan hareketlerden kaynaklandığı, yanlış tekniğin aşırı yaralanmalar için en önemli risk faktörlerinden biri olduğu öne sürülmüştür (20).

Okçularda omuz yaralanmaları incelendiğinde; genel olarak kadınların erkeklerden daha sık olarak omuz yaralanma belirti ve semptomlarına sahip oldukları belirtilmiştir. Yaralanmalar supraspinatus çarpma, tendinit ve infraspinatusteres minör traksiyon tendiniti ile ilișkili bulunmuștur (12).

Türk okçularında gözlenen yaralanma tipleri saptanmaya çalışıldığında; çekme kolu omuzunda 11 yaralanma ve \%14.7 ile yüksek bir oranın var olduğu, buna karşın çekme kol dirseğinde ve aşil tendonunda yaralanma modelleri arasinda en düşük oranların bulunduğu belirtilmiștir. Okçuların özellikle çekme kollarına dikkat etmeleri gerektiği ve yaralanmamak için antrenman öncesi ısınma ve germe egzersizlerini yapmalarının, ağırlık eğitim programlarını güçlendirmeleri, yay ağırlığı ve ok atış sayısına dikkat etmeleri gerektiği vurgulanmıştır (20).

Yetişkin okçularda yaralanmalar incelendiğinde; omuz ekleminin \%49 oranla en fazla yaralanan bölge olduğu saptanmıştır. Yaralanmaların antrenman hacmiyle ilişkili olmadığı, ancak yanlış teknik uygulamalarının yaralanmaya etki edebileceği öne sürülmüştür. Öte yandan, çekme kuvvetinin yaralanmalardan koruyucu bir faktör olduğu söylenmiştir (21).

\section{SONUÇ}

Sonuç olarak, okçularda en çok omuz, boyun ve sırt bölgesinden yaralanmaların meydana geldiği ve bu yaralanmaların en çok kas ağrısı ve zorlanma şeklinde görüldüğü sonucuna varıldı. Okçularda yaralanmaların büyük çoğunluğunun antrenman sırasında kasların yeterli ısındırılmaması ve atış esnasında bu bölgelerin çok fazla ağır yükle karşı karşıya gelmekten kaynaklı olduğu düşünülmektedir. Sporcuların antrenmanlara ve müsabakalara başlamadan önce iyi ısınmalarına özen gösterilmelidir. Omuz, boyun ve sirt bölgelerine yönelik antrenman ve müsabakalardan önce özel ısınma yapılmalıdır. $\mathrm{Bu}$ bölgelerdeki kas yapısını güçlendirecek kuvvet çalışmaları antrenmanların içerisinde ayrı bir bölüm olarak yer almalıdır. Antrenmanlarda yüklenme düzeyine dikkat edilmeli, özellikle bu bölgelere fazla yüklenmeden kaçınılmalıdır. Atış tekniği değerlendirilmeli, doğru teknikte atışın yapıldığından emin olunmalıdır.

\section{KAYNAKLAR}

1. Uğur M, Can S, Şenel K. Çeşitli spor branşlarında kas gücü ve el tercihinin sakatlanma üzerindeki etkisi. Atatürk Üniv BESYO Beden Eğit Spor Bil Derg. 1999;1(1):1-4.

2. Kılıç B, Yücel AS, Gümüşdağ H, et al. Spor yaralanmaları üst ekstremite yaralanmaları kapsamında omuz yaralanmaları ve tedavi yöntemleri. SSTB Int Ref Acad J Sports Health Medical Sci. 2014;12(4):1-26.

3. World Health Organization. International Classification of Functioning, Disability, and Health (ICF). Geneva: World Health Organization, 2001.

4. Timpka T, Jacobsson J, Bickenbach J, et al. What is sport injury? Sports Med. 2014;44:423-8. 
5. Kanbir O. Sporda Sağlık Bilinci ve İlkyardım, 2. Baskı. Bursa: Ekin Kitabevi, 2005; p 21-4.

6. Kalyon TA. Spor Hekimliği: Sporcu Sağlı̆̆ı ve Spor Sakatlıkları, 3. Baskı. Ankara: GATA Basım Evi, 1995; p 177-8.

7. Akhmedov R, Demirhan B, Cicioğlu İ, et al. Injury by regions seen in greco-roman \& freestyle wresting. Turk J Sport Exerc. 2016;18(3):99-107.

8. Ercan S, Çetin C. Kas-iskelet sistemi yaralanmaları: alt ekstremite akut yaralanmaları. Türkiye Klinikleri J Sports Med-Special Topics. 2015;1(3):82-8.

9. Adirim TA, Cheng TL. Overview of injuries in the young athlete. Sports Med. 2003;33(1):75-81.

10. Metin G, Öztürk L, Yücesir İ, et al. Birinci lig düzeyi elit bayan basketbol oyuncularında istirahat ve egzersiz sırasındaki solunum parametreleri. Eurasian J Pulmonol. 2003;5(4):220-6.

11. Akçay L. Sağlık. 20/10 Basketbol Dergisi. TÜBGEV Yayınları. 2003;15:22.

12. Mann DL, Littke N. Shoulder injuries in archery. Can J Sport Sci. 1989;14(2):85-92.

13. Mann DL. Injuries in archery. In: Clinical Practice of Sports Injury Prevention and Care. PAFH Renstrom, Ed, FIMS. Oxford: Blackwell Scientific Pub; 1994, p 665-75.
14. Kahraman T, Genç A, Göz E. The Nordic Musculoskeletal Questionnaire: cross-cultural adaptation into Turkish assessing its psychometric properties. Disabil Rehabil. 2016;38(21):2153-60.

15. Şenel Ö. Profesyonel futbolcularda bir sezon boyunca meydana gelen spor sakatlıkları ve oluşum nedenleri. Gazi BESBD. 1999;4:32-7.

16. Fédération Internationale de tir a l'Arc (FITA). Constitutions and Procedures. Lausanne, Switzerland: FITA, 2000.

17. Karanfilci M, Kabak B, Hamamcılar O, et al. Okçulukta Spor Yaralanmaları. Ankara: Gençlik ve Spor Bakanlığı, 2014.

18. Ertan H, Kentel BB, Tümer T. Reliability and validity testing of an archery chronometer. J Sport Sci Med. 2005;4:95-104.

19. Niestroj CK, Schöffl V, Küpper T. Acute and overuse injuries in elite archers. J Sports Med Phys Fitness. 2017; Sep 22. doi: 10.23736/S0022-4707.17.07828-8.

20. Ertan H. Injury patterns among Turkish archers. The Shield-Res J Phys Ed Sports Sci. 2006;1:19-29.

21. Ergen E, Çirçi E, Lapostolle JC, et al. FITA medical committee archery injuries survey (seniors). In: Sports Medicine and Science in Archery. E Ergen, K Hibner, Eds. Lausanne: FITA, Medical Committee, 2004; p 59-64. 